\title{
Genetic Fidelity Evaluation of Micropropagated Plantlets of Vanda Hybrid 'Dr.Anek'
}

\author{
Rosemol Baby*, P.A. Valsala and Saakre Manjesh \\ Center for Plant Biotechnology and Molecular Biology (CPBMB), College of Horticulture, \\ Kerala Agriculture University, Kerala, India
}

*Corresponding author

\begin{tabular}{|l|}
\hline Ke y w o r d s \\
$\begin{array}{l}\text { Vanda orchids, } \\
\text { Micropropagation, } \\
\text { Genetic fidelity and } \\
\text { ISSR primers }\end{array}$ \\
\hline Article Info \\
\hline $\begin{array}{l}\text { Accepted: } \\
\text { 20 July } 2019 \\
\text { Available Online: } \\
\text { 10 August } 2019\end{array}$ \\
\hline
\end{tabular}

A B S T R A C T

Micropropagation is a highly sought after technique in the commercial production of orchid plants. This has the advantage of providing large number of plants in a short period of time. But a major constrain in the in vitro propagation technique is the somaclonal variation. It is important to produce true to type planting materials especially in case of the hybrids as they are more prone to variations. The true to type nature of the micropropagated plantlets can be confirmed by genetic fidelity analysis. ISSR markers were utilized to confirm the parental nature of the micropropagated plantlets of Vanda hybrid 'Dr.Anek' so as to validate the micropropagation protocol developed at the centre for the hybrid. Mother plants and their respective clones were subjected to clonal fidelity studies using ISSR assay with five ISSR primers reported for Vanda hybrids. ISSR assay was performed to detect the polymorphism in amplification patterns in the region between two SSR's using UBC808, UBC 811, UBC 826, UBC 835 and UBC 841. Further, the amplification profile of mother plants and micropropagated plantlets generated by each selected primers was examined for maximum number of amplicons, polymorphism and molecular weight of amplicons. Percentage of polymorphism generated by each primer was also worked out. In the present study, four mother plants namely M1, M4, M5 and M8 and five each of respective regenerants were analysed for genetic stability using five ISSR primers out of which two primers namely UBC 808 and UBC 835 showed polymorphism. The average polymorphism was observed to be only 1.11 per cent. Monomorphic bands revealed the genetic stability of progenies inherited from their parents indicating the trueto-type nature of plantlets and thus validating the micropropagation protocol developed for the hybrid.

\section{Introduction}

Demand for cut flower orchid hybrids, both in local and international markets and growing interest in the protected cultivation emphasize the need for more number of elite planting materials. One of the major limiting factors for its spread and large scale cultivation in India is the non-availability of good quality and true to type planting material at a 
reasonable price. Morel (1960) was the pioneer in reporting that in vitro techniques could be used to produce orchids on a large scale using shoot apex cultures of Cymbidium species (Begum et al., 2002). Recently tissue culture is being extensively used for Vanda propagation to meet the increasing market demand as well as for the ex-situ conservation of endangered Vanda species. But a major constrain in the in vitro propagation technique is the somaclonal variation.

Somaclonal variation is the genetic variation observed among progeny of plantlets regenerated from somatic cells cultured in vitro. The main reason for this can be attributed to chromosomal rearrangements and spontaneous mutations owing to the culture conditions. This highly limits the practical utility of tissue culture plantlets on commercial scale. Hence it is important to assure the genetic stability and true to type nature of in vitro regenerated plantlets. Clonal fidelity analysis can be used to check the genetic similarity and variation produced among the regenerants and the mother plant.

ISSR markers serve as an important molecular marker for the clonal fidelity analysis in many of the in vitro propagated plants (Alizadeh et al., 2015). These markers have been used in determining the genetic stability in Vanda hybrids (Kishor and Devi, 2009) also. In this context, the genetic stability of micropropagated plantlets of Vanda hybrid 'Dr.Anek' was confirmed at Center for Plant Biotechnology and Molecular Biology (CPBMB), College of Horticulture, Kerala Agriculture University using five selected ISSR primers namely UBC808, UBC 811, UBC 826, UBC 835 and UBC 841.

\section{Materials and Methods}

The study utilized the micropropagated plantlets of 'Dr.Anek' regenerated at CPBMB using a micropropagation protocol standardized at the centre using inflorescence segments. The regenerants at subculture passage eight maintained at the tissue culture lab at CPBMB was used for the clonal fidelity analysis. The cultures were incubated at $26 \pm 2{ }^{\circ} \mathrm{C}$ in an air conditioned culture room with $16 \mathrm{~h}$ photoperiod $\left(30.4 \mu\right.$ moles $\left./ \mathrm{m}^{2} / \mathrm{s}\right)$ from florescent tubes. Humidity in the culture room varied from 60 to 80 per cent according to the prevailing climate. The mother plants were maintained in the net house at CPBMB, College of Horticulture and were named as M1, M4, M5 and M8 for the sake of convinence of the researcher.

The protocol for micropropagation of 'Dr.Anek' standardized at CPBMB using inflorescence segments was $1 / 2 \mathrm{MS}+10 \mathrm{mg} \mathrm{l}^{-}$ 1 2,4-D + $1 \mathrm{mg} \mathrm{l}^{-1} \mathrm{TDZ}+30 \mathrm{~g} \mathrm{l}^{-1}$ sucrose + $7.5 \mathrm{~g} \mathrm{l}^{-1}$ agar $+250 \mathrm{mg} \mathrm{l}^{-1}$ cefotaxime for culture establishment, $\mathrm{MS}+4.5 \mathrm{ml} \mathrm{l}^{-1} \mathrm{BA}+$ $30 \mathrm{~g} \mathrm{l}^{-1}$ sucrose $+7.5 \mathrm{~g} \mathrm{l}^{-1}$ agar $+250 \mathrm{mg} \mathrm{l}^{-1}$ cefotaxime for shoot proliferation and $\mathrm{MS}+$ $0.5 \mathrm{mg} \mathrm{l}^{-1} \mathrm{NAA}+1 \mathrm{mg} \mathrm{l}^{-1} \mathrm{IAA}+30 \mathrm{~g} \mathrm{l}^{-1}$ sucrose $+7.5 \mathrm{~g} \mathrm{l}^{-1}$ agar $+250 \mathrm{mg} \mathrm{l}^{-1}$ cefotaxime for rooting.

In the experiment, DNA was isloated from all the mother plants and their respective clones using CTAB procedure reported by Rogers and Bendich (1994) from young tender leaves and was purified by RNase (Promega, Wisconsin, USA) treatment (Sambrook et al., 1989).The integrity and quality of DNA samples were assessed through agarose gel $(0.8 \%)$ and Nanodrop ND-1000 spectrophotometer, respectively.good quality genomic DNA (50 to $100 \mathrm{ng} / \mu \mathrm{l}$ ) was subjected to ISSR assay using 5 selected primers after an initial screening of 8 ISSR primers reported in Vanda hybrids.Further, DNA amplification was done in Agilent thermocycler as per the PCR conditionsPCR amplification were performed in the $20 \mu \mathrm{L}$ reaction mixture, using $2 \mu$ LGenomic DNA 
$(50 \mathrm{ng} / \mu \mathrm{l})$. Each reaction mixture contained 2 $\mu \mathrm{L}$ of $10 \mathrm{X}$ Taq assay buffer, $2 \mu \mathrm{L} \mathrm{MgCl} 2,1.5$ $\mu \mathrm{L}$ dNTPs, $1.5 \mu \mathrm{L}$ primers, $10 \mu \mathrm{LAutoclaved}$ distilled water and $0.4 \mu \mathrm{LTaq}$ DNA polymerase $(3 \mathrm{U})(25 \mathrm{mmol} / \mathrm{L})$. The reactions were performed using a thermal cycler programmed to initial denaturation at $94{ }^{\circ} \mathrm{C}$ for $2 \mathrm{~min}$, denaturation at $94{ }^{\circ} \mathrm{C}$ for $30 \mathrm{~s}$ followed by annealing at $48^{\circ} \mathrm{C}$ to $58^{\circ} \mathrm{C}$ for 1 min, extension at $72{ }^{\circ} \mathrm{C}$ for 1 min for 35 cycles and then followed by final extension at $72{ }^{\circ} \mathrm{C}$ for $5 \mathrm{~min}$.Amplification profile of mother plants and micropropagated plantlets generated by each selected primers was examined for maximum number of amplicons, polymorphism and molecular weight of amplicons. Percentage of polymorphism generated by each primer was worked out as given below:

Percentage of polymorphism $=$

Number of polymorphic bands $\times 100$

Total number of bands

\section{Results and Discussion}

The genomic DNA was isolated from tender leaf samples collected from mother plants as well as from the regenerated clones using CTAB method. The experiment also screened 8 different ISSR primers with good quality DNA isolated from one mother plant. The documented ISSR profiles were carefully examined for total number amplicons generated by each primer and this allowed the selection of primers giving DNA amplification for further analysis. The optimum temperatures for DNA amplification by each primer were also identified. The results of primer screening are presented in Table 1 and out of 8 primers, 5 were selected for the study.

ISSR primers are now proved to be much more efficient in assessing the genetic integrity among clonally propagated plants as reported by many workers in different species (Zietekiewicz et al., 1994; Bhatia etal., 2011; Vanijajiva, 2012). High reproducibility with ISSR technique is attributable to the use of longer primers allowing for higher annealing temperatures than those of RAPDs (Pradeep et al., 2002). ISSR markers require only little amount of DNA sample, does not involve any radioactivity tests and are simple as well as faster. Hence ISSR markers have been successfully applied to detect the genetic similarities or dissimilarities in micropropagated material in various plants (Carvalho et al., 2004).

Four mother plants with five clones each were compared for their DNA amplification pattern using the five selected ISSR primers. The amplification patterns obtained for each of the primers are detailed below:

\section{UBC 808}

Amplification with the primer UBC 808 generated eight clear amplicons in 4 clones out of 5 tested in mother plant 1 of Dr.Anek. The bands obtained were in the size range of 250-1200 bp. The amplified DNA profile showed one polymorphic band of 1000bp size in one of the clones $\left(\mathrm{C}_{1}\right)$ among five for one mother plant (M1) which was absent for other clones (Fig.2).In all other mother plants of Dr.Anek (M4, M5 and M8) all clones as well as mother plants showed monomorphic bands which showed that the clones are exactly similar to the mother plants.

\section{UBC 811}

Amplification with the primer UBC 811 generated nine clear amplicons in all clones of all four tested mother plants of Dr.Anek. The bands obtained were all monomorphic bands in the size range of 150-1200 bp. Monomorphic banding pattern was observed for all the amplified band classes across the mother plant and its regenerants. The 
amplification pattern for primer UBC 811 for the four mother plants and their respective clones detailed in Fig.3.

\section{UBC 826}

Amplification with the primer UBC 826 generated nine clear amplicons in all clones of all four tested mother plants of Dr.Anek. The bands obtained were all monomorphic in the size range of 150-1200 bp. The monomorphic bands obtained in the ISSR analysis with UBC 826 primer showed that the clones regenerated through the identified in vitro propagation protocol are exactly similar to the mother plants. The amplification pattern for primer UBC 826 for the four mother plants and their respective clones are detailed in Fig.4.

\section{UBC 835}

Amplification with the primer UBC 835 generated eleven clear amplicons in all clones of all four tested mother plants of Dr.Anek and bands obtained were in the size range of 300- $2000 \mathrm{bp}$. In one clone of mother plant $1\left(C_{3}\right.$ of $\left.M 1\right)$, there was the absence of a band of $850 \mathrm{bp}$ size which showed variation in genetic content of clone 3 (Fig. 5). The other monomorphic bands obtained in the ISSR analysis with UBC 835 primers showed that the clones regenerated through the identified in vitro propagation protocol are exactly similar to the mother plants whereas the polymorphic band showed that the particular clone may have difference in some traits. Theamplification pattern for primer UBC 835 for the four mother plants and their respective clones are provided in Fig 5.

\section{UBC 841}

Amplification with the primer UBC 841 generated eight clear amplicons in all clones of all four tested mother plants of Dr.Anek.
All the bands obtained were monomorphic in all four mother plants in the size range of 300$800 \mathrm{bp}$. The monomorphic bands obtained in the ISSR analysis with UBC 841 primers showed that the clones regenerated through the identified in vitro propagation protocol are identical to the mother plants. The amplification pattern for primer UBC 841 for the four mother plants and their respective clones are given in Fig. 6

In the present study, ISSR marker assay was employed to validate the clonal fidelity of in vitro raised Vanda plantlets multiplied using inflorescence segments. With five primers tested, UBC 808 and UBC 835 exhibited polymorphism while all the other primers gave monomorphic amplicons in the size range of $150 \mathrm{bp}$ to $2000 \mathrm{bp}$. The number of scorable bands for each primer varied from 8 to 11. A total of 180 bands were generated from mother plant and regenerants, out of which 178 were monomorphic and only 2 clones showed polymorphic bands. Primer UBC 808 showed 3.13 per cent polymorphism whereas UBC 835 showed only 2.27 per cent polymorphism between clones and their mother. The average polymorphism was observed to be 1.11 per cent (Table 2).

The polymorphism may be due to somoclonal variation or by addition of antibiotics in the cultureing medium. Monomorphic bands reveal the genetic stability of progenies inherited from their parents indicating the true-to-type nature of plantlets.Kishor and Devi (2009) analysed clonal fidelity for orchid hybrid Aeridesvandarum $\times$ Vanda stangeana using ISSR primers and found 100 per cent monophorphism in clones with respect to their parents. In a similar study, Joshi and Dhawan (2007) have employed ISSR marker assay to validate the genetic fidelity of Swertiachirayita plantlets multiplied in vitro by axillary multiplication 
uptoforty-two passages. Gantait et al., (2010) reported the clonal fidelity of micropropagated and sustained cultured clones of Allium ampeloprasum L. using ISSR primers.

Table.1 Details of ISSR primers screened

\begin{tabular}{|l|l|l|c|c|c|c|}
\hline $\begin{array}{c}\text { Sl. } \\
\text { No. }\end{array}$ & Primers & \multicolumn{1}{|c|}{ Nucleotide Sequence (5'-3') } & Size range & $\begin{array}{c}\text { Total } \\
\text { number of } \\
\text { bands }\end{array}$ & $\begin{array}{c}\text { Annealing } \\
\text { temperature } \\
\left({ }^{\circ} \mathbf{C}\right)\end{array}$ & Comments \\
\hline $\mathbf{1}$ & UBC 808 & 5'AGAGAGAGAGAGAGAGC 3' & $250-1200$ & 8 & 54 & Selected \\
\hline $\mathbf{2}$ & UBC 811 & 5'GAGAGAGAGAGAGAGAC 3' & $150-1200$ & 9 & 58 & Selected \\
\hline $\mathbf{3}$ & UBC 818 & 5' CACACACACACACACAG 3' & - & - & - & Not selected \\
\hline $\mathbf{4}$ & UBC 826 & 5'ACACACACACACACACC 3' & $150-1200$ & 9 & 53 & Selected \\
\hline $\mathbf{5}$ & UBC 835 & 5'AGAGAGAGAGAGAGAGYC 3' & $300-2000$ & 11 & 49 & Selected \\
\hline $\mathbf{6}$ & UBC 841 & 5' GAGAGAGAGAGAGAGAYC 3' & $300-800$ & 8 & 46 & Selected \\
\hline $\mathbf{7}$ & UBC 847 & 5' CACACACACACACACARC 3' & - & - & - & Not selected \\
\hline $\mathbf{8}$ & UBC 850 & 5' GTGTGTGTGTGTGTGTYC 3' & - & - & - & Not selected \\
\hline
\end{tabular}

Table.2 DNA Amplification pattern in 'Dr.Anek'

\begin{tabular}{|c|c|c|c|c|c|c|}
\hline \begin{tabular}{|l} 
Sl. \\
No
\end{tabular} & \multicolumn{2}{|c|}{ Primer name } & \multirow{2}{*}{$\begin{array}{c}\begin{array}{c}\text { Total No. of } \\
\text { amplicons }\end{array} \\
8 \\
\end{array}$} & \multirow{2}{*}{$\begin{array}{c}\begin{array}{c}\text { No. of } \\
\text { polymorphic } \\
\text { amplicons }\end{array} \\
0 \\
\end{array}$} & \multirow{2}{*}{$\begin{array}{c}\begin{array}{c}\text { No. of monomorphic } \\
\text { amplicons }\end{array} \\
8 \\
\end{array}$} & \multirow{2}{*}{$\begin{array}{c}\begin{array}{c}\text { Polymorphism } \\
(\%)\end{array} \\
3.13\end{array}$} \\
\hline 1 & \multirow{4}{*}{$\begin{array}{c}\text { UBC } \\
808\end{array}$} & M1 & & & & \\
\hline & & M4 & 8 & 0 & 8 & \\
\hline & & M5 & 8 & 1 & 7 & \\
\hline & & M8 & 8 & 0 & 8 & \\
\hline \multirow[t]{4}{*}{2} & \multirow{4}{*}{$\begin{array}{c}\text { UBC } \\
811\end{array}$} & M1 & 9 & 0 & 9 & \multirow[t]{4}{*}{0} \\
\hline & & M4 & 9 & 0 & 9 & \\
\hline & & M5 & 9 & 0 & 9 & \\
\hline & & M8 & 9 & 0 & 9 & \\
\hline \multirow[t]{4}{*}{3} & \multirow{4}{*}{$\begin{array}{c}\text { UBC } \\
826\end{array}$} & M1 & 9 & 0 & 9 & \multirow[t]{4}{*}{0} \\
\hline & & M4 & 9 & 0 & 9 & \\
\hline & & M5 & 9 & 0 & 9 & \\
\hline & & M8 & 9 & 0 & 9 & \\
\hline \multirow[t]{4}{*}{4} & \multirow{4}{*}{$\begin{array}{c}\text { UBC } \\
835\end{array}$} & M1 & 11 & 1 & 10 & \multirow[t]{4}{*}{2.27} \\
\hline & & M4 & 11 & 0 & 11 & \\
\hline & & M5 & 11 & 0 & 11 & \\
\hline & & M8 & 11 & 0 & 11 & \\
\hline \multirow[t]{6}{*}{5} & \multirow{4}{*}{$\begin{array}{c}\text { UBC } \\
841\end{array}$} & M1 & 8 & 0 & 8 & \multirow[t]{4}{*}{0} \\
\hline & & M4 & 8 & 0 & 8 & \\
\hline & & M5 & 8 & 0 & 8 & \\
\hline & & M8 & 8 & 0 & 8 & \\
\hline & \multicolumn{2}{|c|}{ Total } & 180 & 2 & 178 & 1.11 \\
\hline & \multicolumn{2}{|c|}{ Average } & 9.0 & 0.10 & 8.9 & \\
\hline
\end{tabular}


Fig.1 (a and b) Gel pictures showing the DNA samples of mother plants

a)

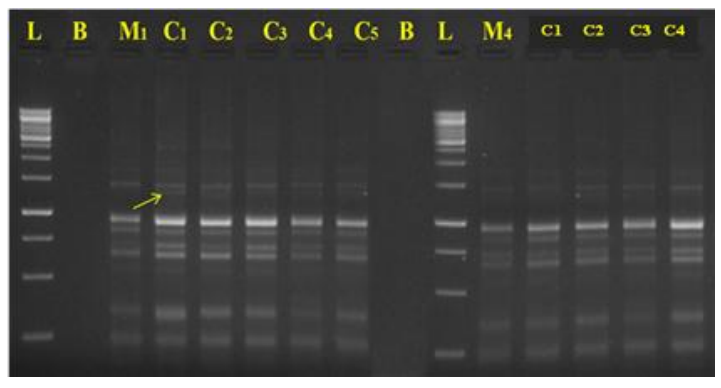

b)

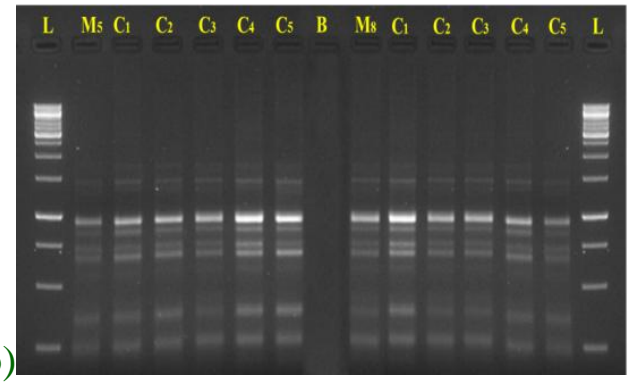

a). L: Marker $(12 \mathrm{~kb})$; B: Blank; $\mathrm{M}_{1}$ : Mother plant 1 of Dr.Anek; $\mathrm{C}_{1}-\mathrm{C}_{5}$ : Clones of $\mathrm{M}_{1}$; $\mathrm{M}_{4}$ : Mother plant 4 of Dr.Anek; $\mathrm{C}_{1}-\mathrm{C}_{4}$ : Clones of $\mathrm{M}_{4}$

(b). L: Marker $(12 \mathrm{~kb})$; B: Blank; $\mathrm{M}_{5}$ : Mother plant 5 of Dr.Anek; $\mathrm{C}_{1}-\mathrm{C}_{5}$ : Clones of $\mathrm{M}_{5} ; \mathrm{M}_{8}$ : Mother plant 8 of Dr.Anek; $\mathrm{C}_{1}-\mathrm{C}_{5}$ : Clones of $\mathrm{M}_{8}$

Fig.2 (a and b) Amplification pattern for UBC 808 for different mother plants and their respective clones of 'Dr.Anek'
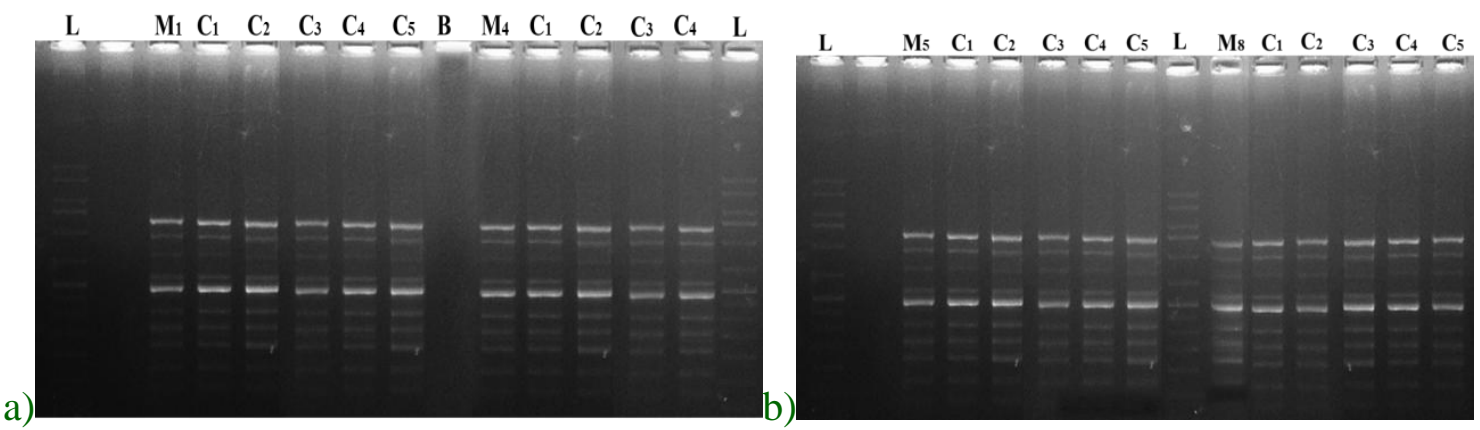

(a). L: Marker (3kb); B: Blank; $\mathrm{M}_{1}$ : Mother plant 1 of Dr.Anek; $\mathrm{C}_{1}-\mathrm{C}_{5}$ : Clones of $\mathrm{M}_{1}$; $\mathrm{M}_{4}$ : Mother plant 4 of Dr.Anek; $\mathrm{C}_{1}-\mathrm{C}_{4}$ : Clones of $\mathrm{M}_{4}$

(b). L: Marker $(3 \mathrm{~kb})$; B: Blank; $\mathrm{M}_{5}$ : Mother plant 5 of Dr.Anek; $\mathrm{C}_{1}-\mathrm{C}_{5}$ : Clones of $\mathrm{M}_{5} ; \mathrm{M}_{8}$ : Mother plant 8 of Dr.Anek; $\mathrm{C}_{1}-\mathrm{C}_{5}$ : Clones of $\mathrm{M}_{8}$

Fig.3 (a and b) Amplification pattern for UBC 811 for different mother plants and their respective clones of 'Dr.Anek'
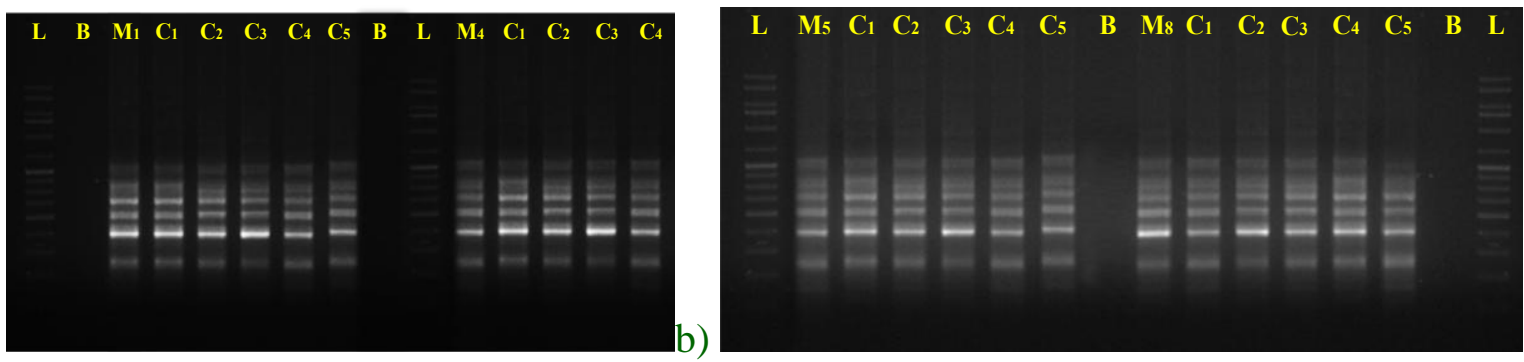

(a). L: Marker (3 kb); B: Blank; $\mathrm{M}_{1}$ : Mother plant 1 of Dr.Anek; $\mathrm{C}_{1} \mathrm{C}_{5}$ : Clones of $\mathrm{M}_{1} ; \mathrm{M}_{4}$ : Mother plant 4 of Dr.Anek; $\mathrm{C}_{1}-\mathrm{C}_{4}$ : Clones of $\mathrm{M}_{4}$

(b). L: Marker $(3 \mathrm{~kb})$; B: Blank; $\mathrm{M}_{5}$ : Mother plant 5 of Dr.Anek; $\mathrm{C}_{1}-\mathrm{C}_{5}$ : Clones of $\mathrm{M}_{5} ; \mathrm{M}_{8}$ : Mother plant 8 of Dr.Anek; $\mathrm{C}_{1}-\mathrm{C}_{5}$ : Clones of $\mathrm{M}_{8}$ 
Fig.4 (a and b) Amplification pattern for UBC 826 for different mother plants and their respective clones of 'Dr.Anek'

a)
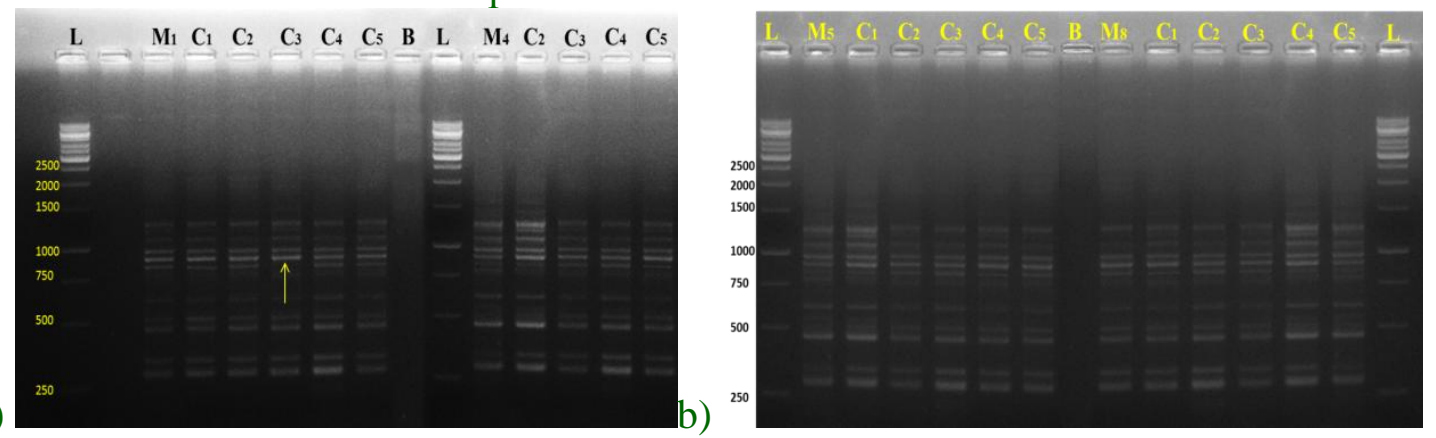

(a). L: Marker (12 kb); B: Blank; $\mathrm{M}_{1}$ : Mother plant 1 of Dr.Anek; $\mathrm{C}_{1}-\mathrm{C}_{5}$ : Clones of $\mathrm{M}_{1} ; \mathrm{M}_{4}$ : Mother plant 4 of Dr.Anek; $\mathrm{C}_{1}-\mathrm{C}_{4}$ : Clones of $\mathrm{M}_{4}$

(b). L: Marker (12 kb); B: Blank; $\mathrm{M}_{5}$ : Mother plant 5 of Dr.Anek; $\mathrm{C}_{1}-\mathrm{C}_{5}$ : Clones of $\mathrm{M}_{5} ; \mathrm{M}_{8}$ : Mother plant 8 of Dr.Anek; $\mathrm{C}_{1}-\mathrm{C}_{5}$ : Clones of $\mathrm{M}_{8}$

Fig.5 (a and b) Amplification pattern for UBC 835 for different mother plants and their respective clones of 'Dr.Anek'

a)
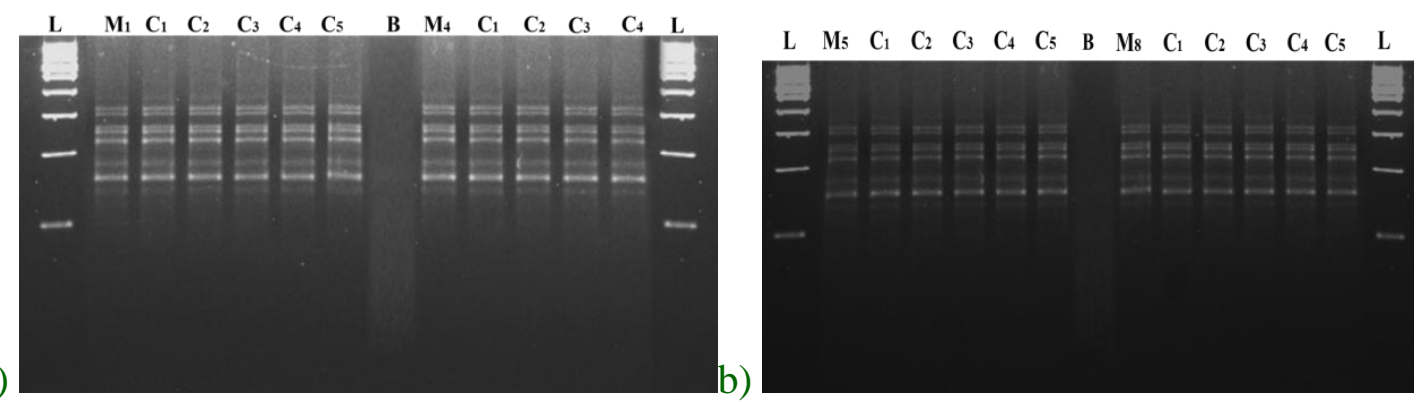

(a). L: Marker (12 kb); B: Blank; $\mathrm{M}_{1}$ : Mother plant 1 of Dr.Anek; $\mathrm{C}_{1}-\mathrm{C}_{5}$ : Clones of $\mathrm{M}_{1} ; \mathrm{M}_{4}$ : Mother plant 4 of Dr.Anek; $\mathrm{C}_{1}-\mathrm{C}_{4}$ : Clones of $\mathrm{M}_{4}$

(b). L: Marker (12 kb); B: Blank; $\mathrm{M}_{5}$ : Mother plant 5 of Dr.Anek; $\mathrm{C}_{1}-\mathrm{C}_{5}$ : Clones of $\mathrm{M}_{5} ; \mathrm{M}_{8}$ : Mother plant 8 of Dr.Anek; $\mathrm{C}_{1}-\mathrm{C}_{5}$ : Clones of $\mathrm{M}_{8}$

Fig.6 ( $a$ and b). Amplification pattern for UBC 841 for different mother plants and their respective clones of 'Dr.Anek'

In the present study, per cent polymorphism was calculated only to 1.11 per cent. This results show that the protocol identified for in vitro regeneration of Vanda hybrids can maintain the genetic stability of the mother plants and is suitable to obtain true to type plantlets. Similar observations were reported by Kishor and Devi (2009) in Vanda hybrid Aerides vandarum $\mathrm{x}$ Vanda stangeana. Across the randomly selected mother plants and nine of its regenerants, they could obtain monomorphic banding profiles. The molecular analysis of the mother plants and clones did not show any genomic alterations for the shoots regenerated on $2 \mathrm{mg} \mathrm{l}^{-1} \mathrm{TDZ}$ which was in accordance with the present study.

Goto et al., (1998) reported that the presence or absence of variations during in vitro propagation depends upon the source of explants and the method of regeneration. 
Martins et al., (2004) reported that suboptimal levels of plant growth substances, especially synthetic plant growth hormones, have also been associated with somaclonal variation. Even at optimal levels, longterm multiplication and high chromosome number of the plant may often lead to somaclonal or epigenetic variations in micropropagated plants, consequently, questioning fidelity of their clonal nature. In present study, regenerated plantlets were obtained with very little variation.

In conclusion, the results of the experiment showed that CTAB method is an effective procedure for isolation of good quality DNA from Vanda orchids. The quality of the DNA isolated ranged between 1.77 to 1.98 in terms of UV absorbance at 260/280 $\left(\mathrm{A}_{260 / 280}\right)$. The study showed positive results for the ISSR marker analysis. UBC primers reported in Vanda orchids were utilized in the present study and showed similar observations. UBC 808, UBC 11, UBC 826, UBC 835 and UBC 841 can be used for the genetic stability evaluation of Vanda hybrids. Out of the 5 primers used, only two primers showed polymorphic bands and the average percentage polymorphism was only 1.11 . This confirms the clonal fidelity of the regenerants of Dr.Anek multiplied using inflorescence segments. The study also validates the invitro micropropagation protocol developed at the Centre and the protocol developed can be used for commercial production.

\section{Acknowledgement}

I am thankful to Center for Plant Biotechnology and Molecular Biology (CPBMB), College of Horticulture, Kerala Agriculture University, Thrissur, for providing the germplasm, laboratory and other facilities for conducting the research.

\section{References}

Alizadeh, M., Krishna, H., Eftekhari, M., Modareskia, M., and Modareskia, M. 2015.Assessment of clonal fidelity in micropropagated horticultural plants.J. Chem. Pharma. Res. 7 (12):977-990.

Begum, F., Islam, D., Paul, R. N., Mehedi, M., and Mondal, S. R. 2002.In vitro propagation of Vanda pteris through axillary bud derived protocorm culture. Trop. Agric. Res. Ext.5:1-4.

Gallego, F. J. and Martinez, I. 1996. Molecular typing of rose cultivars using RAPDs.J. Horitic. Sci. 71:901-908.

Kishor, R. and Devi, H. S. 2009.Induction of multiple shoots in a monopodial orchid hybrid (Aerides vandarum Reichb.F x Vanda stangeana Reichb.f) using thidiazuron and analysis of their genetic stability. Plant Cell Tiss.Organ Cult.97: 121-129.

Morel, G. 1960. Producing virus free Cymbidiums. Am. Orchid Soc. Bull.29: 495-497.

Raval, V., Goldberg, S., Atkinson, L., Benoit, D., Myhal, N., Poulton, L., and Zwiers, M. 1998.Maternal attachment, maternal responsiveness and infant attachment. Infant Behav. Dev.24:281-304.

Rogers, S. O. and Bendich, A. J. 1994. Extraction of total cellular DNA from plants, algae and fungi. In: Plant Molecular Biology Manual. Springer, Netherlands pp183-190.

Sambrook, J., Fritsch, E. F., and Maniatis, T. 1989. Molecular Cloning. A Laboratory Mannual. Academic Press, New York, USA, 1322p.

Wettasinghe, R. and Peffley, E. B. 1998. A rapid and efficient extraction method for onion DNA. Plant Breed.117:588589. 


\section{How to cite this article:}

Rosemol Baby, P.A. Valsala and Saakre Manjesh. 2019. Genetic Fidelity Evaluation of Micropropagated Plantlets of Vanda Hybrid 'Dr.Anek'. Int.J.Curr.Microbiol.App.Sci. 8(08): 2373-2381. doi: https://doi.org/10.20546/ijcmas.2019.808.276 